\title{
Preference of Traditional Bone Setting and associated factors among trauma patients with fracture at Black Lion Hospital in Addis Ababa, Ethiopia: institution based cross sectional study
}

\author{
Nardos Worku', Tsegaye Tewelde², Biru Abdissa ${ }^{3}$ and Hailu Merga ${ }^{2 *}(0)$
}

\begin{abstract}
Objective: Despite the access and availability of modern health care, Traditional Bone Setting (TBS) has a big place as alternative health care. Hence, this study was aimed to assess the preference of Traditional Bone Setting and associated factors among patients with a fracture.

Results: A total of 224 patients known to have fractured at Black Lion Hospital, Addis Ababa was included in the study. This study revealed that $29.9 \%$ of the study participants had a preference for the Traditional Bone Setting. Hospital admission ( $A O R=8.158,95 \% \mathrm{Cl} 1.179,56.439)$, Traditional Bone Setting center as first port of call after injury $(A O R=0.004,95 \% \mathrm{Cl} 0.001,0.090)$, knowledge $(A O R=9.448,95 \% \mathrm{Cl} 1.481,60.251)$ and perception $(A O R=0.026,95 \%$ $\mathrm{Cl} 0.003,0.215)$ were statistically significant. The preference for the Traditional Bone Setting is high. Hospital admission, Traditional Bone Setting center as a first port of call after injury, knowledge, and perception were significantly associated with the preference of Traditional Bone Setting. In addition to deployment of trained in trauma professionals, working more on awareness creation and training are recommended.
\end{abstract}

Keywords: Preference, Traditional Bone Setting, Associated factors, Black Lion Hospital, Ethiopia

\section{Introduction}

Fracture can occur because of trauma like a road traffic accident or a fall $[1,2]$. Traditional medicine is a health practice and traditional knowledge and skill of medical aspects that passed over a generation before the era of modern medicine [3]. TBS, widely practiced all over the world before modern medicine comes into the picture, is also a known procedure among Africans and it involves the use of splints and bamboo stick or rattan cane or palm leaf axis with cotton thread or old cloth [4]. Traditional bone setter is a lay practitioner who practices

\footnotetext{
*Correspondence: hailu.merga2014@gmail.com

2 Department of Epidemiology, Institute of Health, Jimma University, Jimma, Ethiopia

Full list of author information is available at the end of the article
}

management of dislocations and fractures without having had any formal training. Despite the access and availability of modern health care, Traditional Bone Setting (TBS) has a big place as an alternative health care [5]. Evidences indicated that $80 \%$ of the people in SSA use traditional medicine as a first port $[6,7]$. In several studies, the reason for the preference of TBS includes easy accessibility, cultural belief, quick service, cheaper fee, pressure from friends and families and utilization of incantation and concoctions [8-13].

Evidences from Ethiopia showed half of the amputations were performed due to gangrene applied by TBS [14]. There are increasing complications like gangrene associated with TBS as a result of tightly wrapped bamboo splint application [15]. The number of trauma patients with a fracture is dramatically increasing in 
Ethiopia due to majorly sharp rise in the incidence of road traffic accidents. A study from Black Lion Hospital showed $58 \%$ of amputations performed for gangrene were caused by TBS tight bamboo splint [14]. Another study conducted in Addis Ababa showed the TBS as the leading cause of delay for modern treatment [16]. However, there was no finding on the efficacy of TBS in comparison to modern medicine. Therefore, this study aimed to assess the preference of TBS and associated factors among patients with a fracture which can be an eye opener to integrate them into the primary health care system.

\section{Main text Methods \\ Study design and sampling}

Hospital-based cross-sectional study design was conducted in Black Lion Hospital, Addis Ababa from March 5 to April 30, 2018. It is the largest government hospital serving about 370,000-400, 000 populations a year. The Adult Orthopedic outpatient department sees around 10,000 patients a year out of which 5000 were patients with fractures. Eighteen years and above trauma patients with fracture and visiting the outpatient department during the data collection period were included in the study. However, Patients who seek medical care elsewhere before coming to the Hospital and patients with fractures other than upper extremity, lower extremity or pelvis were excluded from the study.

The sample size was determined using a single population proportion formula by considering: $95 \%$ confidence interval, $84 \%$ proportion of patients Preferring TBS as first-line treatment [17] and 5\% marginal error. Then, after considering a $10 \%$ for non-response rate, 227 sample sizes was taken using systematic random sampling. On average 350 to 450 fractured patients were seen every month. Therefore, on average 700 patients were expected to visit the OPD during the study period (7 weeks) and the sample size was 227 which is one-third of the total patients expected to be seen during the study period. By taking the final sample size, patients were recruited in the study every three intervals and the first patient was selected by lottery method.

Data were collected by two Nurses using a pretested structured questionnaire developed after reviewing literature $[14,15,17]$. Face-to-face exit interview was undertaken at the Orthopedic Department Adult OPD clinic. In this study, knowledge was measured using eleven knowledge related questions and answering nine questions and above was used as a cutoff point to label them knowledgeable [18].

\section{Analysis}

STROBE checklist was used to analyze and report data [19]. Data were entered into EpiInfo and exported to SPSS software for analysis. Descriptive analyses were performed and binary logistic regression was performed. $p$ value $<0.05$ and $95 \%$ confidence interval $(\mathrm{CI})$ and $A O R$ was used in judging the statistical significance of the associations between independent variables and the outcome variable.

\section{Results}

\section{Socio-demographic characteristics}

Among 227 study participants, 224 responded making the response rate $98.7 \%$. More than half of the study participants were male and $40.2 \%$ of them were more than 40 years. One hundred seven $(47.8 \%)$ of the study participants were Orthodox Christians. Majority of respondents were urban residents and more than half of them were married. More than one-third, $38.8 \%$, of the study participants had completed secondary school (Table 1).

\section{Injury and preference related factors}

The study revealed that more than half of the respondents were injured due to the road traffic accident. One hundred nine $(48.7 \%)$ of them were admitted to hospital for injury and from those $30.3 \%$ of them had a complication during admission (Table 2). One hundred seventyseven $(79.0 \%)$ of the study participants had no associated injury other than extremity injury. Nearly one-third, $30.3 \%$ of the study participants had a complication during admission and $27.3 \%$ of them had surgical site infection.

\section{Knowledge and perception}

From the total, 213 (95.1\%) heard about the TBS and $58.9 \%$ of the respondents knew that the drawbacks of TBS. Two hundred twenty (98.2\%) of the study participants heard about modern orthopedic care; however, only $42.4 \%$ of the respondents were knowledgeable about TBS. About one-fourth, 25.9\%, of the study participants perceived that TBS is better than health facilities treatment. Out of $58 \%$ who knew drawback of TBS, $36.9 \%$ of them identified lack of proper knowledge and skill as a drawback of TBS.

Most of the study participants (96.4\%) thought that TBS is cheaper and $92.9 \%$ of them thought that TBS has quick services than health facilities. More than half of the respondents, $(53.6 \%)$ did not think that the nearby health facilities have enough service providers. The study showed $40.6 \%$ of them had their family member/relative encountered injury in the past and in which more than half, $61.5 \%$, of them were managed by traditional bone setters. 
Table 1 Socio-demographic characteristics of study participants in Black Lion Hospital, $2018(n=224)$

\begin{tabular}{|c|c|c|}
\hline Variables & Frequency & Percent (\%) \\
\hline \multicolumn{3}{|l|}{ Sex } \\
\hline Male & 131 & 58.5 \\
\hline Female & 93 & 41.5 \\
\hline \multicolumn{3}{|l|}{ Age in years } \\
\hline $18-30$ & 81 & 36.2 \\
\hline $31-40$ & 53 & 23.6 \\
\hline$>40$ & 90 & 40.2 \\
\hline \multicolumn{3}{|l|}{ Residency } \\
\hline Urban & 135 & 60.3 \\
\hline Rural & 89 & 39.7 \\
\hline \multicolumn{3}{|l|}{ Marital status } \\
\hline Single & 62 & 27.7 \\
\hline Married & 133 & 59.4 \\
\hline Separated/divorced & 20 & 8.9 \\
\hline Widowed & 9 & 4.0 \\
\hline \multicolumn{3}{|l|}{ Educational status } \\
\hline No formal education & 46 & 20.5 \\
\hline Primary school & 47 & 21.0 \\
\hline Secondary school & 87 & 38.8 \\
\hline Tertiary school and above & 44 & 19.6 \\
\hline \multicolumn{3}{|l|}{ Occupation } \\
\hline Civil servant & 55 & 24.6 \\
\hline Private employee & 29 & 12.9 \\
\hline Own business & 47 & 21.0 \\
\hline Farmer & 25 & 11.2 \\
\hline Daily laborer & 15 & 6.7 \\
\hline Unemployed & 53 & 23.7 \\
\hline \multicolumn{3}{|l|}{ Religion } \\
\hline Orthodox & 107 & 47.8 \\
\hline Protestant & 52 & 23.2 \\
\hline Muslim & 47 & 21.0 \\
\hline Catholic & 18 & 8.0 \\
\hline \multicolumn{3}{|l|}{ Ethnicity } \\
\hline Oromo & 68 & 30.4 \\
\hline Amhara & 74 & 33.0 \\
\hline Gurage & 53 & 23.7 \\
\hline Tigre & 22 & 9.8 \\
\hline Others $^{\mathrm{a}}$ & 7 & 3.1 \\
\hline \multicolumn{3}{|l|}{ Average monthly income } \\
\hline$\leq 4500 \mathrm{ETB}$ & 113 & 50.4 \\
\hline$>4500$ ETB & 111 & 49.6 \\
\hline
\end{tabular}

a Harari, Somali, and Gambella ethnic groups

\section{Preference of injury management and associated Factors}

This study showed $29.9 \%$ (95\% CI 23.7, 36.6) of them had a preference for TBS for injury management. Bivariate analysis showed; sex, residency, marital status, educational status, religion, ethnicity, average monthly income,
Table 2 Injury and preference related factors among study participants in Black Lion Hospital, 2018

\begin{tabular}{|c|c|c|}
\hline Variables & Frequency & Percent (\%) \\
\hline \multicolumn{3}{|l|}{ Mechanism of injury $(n=224)$} \\
\hline Road traffic accident & 116 & 51.8 \\
\hline Falling accident & 84 & 37.5 \\
\hline Domestic accident & 22 & 9.8 \\
\hline Others (gunshot, water tube fall) & 2 & 0.9 \\
\hline \multicolumn{3}{|l|}{ Type of injury $(n=224)$} \\
\hline Upper extremity & 97 & 43.3 \\
\hline Lower extremity & 104 & 46.4 \\
\hline Pelvic fracture & 23 & 10.3 \\
\hline \multicolumn{3}{|c|}{ Associated injury other than extremity injury $(n=224)$} \\
\hline Yes & 47 & 21.0 \\
\hline No & 177 & 79.0 \\
\hline \multicolumn{3}{|c|}{ Admission to a hospital for injury $(n=224)$} \\
\hline Yes & 109 & 48.7 \\
\hline No & 115 & 51.3 \\
\hline \multicolumn{3}{|c|}{ Complication during admission $(n=109)$} \\
\hline Yes & 33 & 30.3 \\
\hline No & 76 & 69.7 \\
\hline \multicolumn{3}{|l|}{ Condition during admission $(n=109)$} \\
\hline Critical & 39 & 35.8 \\
\hline Stable & 67 & 61.5 \\
\hline Don't know & 3 & 2.8 \\
\hline \multicolumn{3}{|l|}{ Condition during discharge $(n=109)$} \\
\hline Improved & 86 & 78.7 \\
\hline Cured & 10 & 9.3 \\
\hline Same & 13 & 12.0 \\
\hline \multicolumn{3}{|c|}{ TBS center first port of call after injury $(n=224)$} \\
\hline Yes & 114 & 50.9 \\
\hline No & 110 & 49.1 \\
\hline
\end{tabular}

type of injury, associated injury other than extremity injury, hospital admission for injury, TBS center first port of call after injury, knowledge, perception, fear of operation/amputation in health facility, lack of satisfaction from health facility service, time taken to reach TBS, time taken to reach modern health facility, and family/relative history of injury were significantly associated with preference of TBS among trauma patients with fracture.

Multivariable logistic regression analysis revealed those trauma patients who were not admitted in a hospital for injury were about eight times more likely to prefer TBS for injury management than those trauma patients who were admitted in a hospital for injury (AOR $=8.158,95 \%$ CI 1.179, 56.439).

Those trauma patients who didn't use TBS center as their first port of call after injury were $99.6 \%$ less likely to prefer TBS for injury management as compared to 
Table 3 Factors associated with the preference of injury management among trauma patients with a fracture in Black Lion Hospital, $2018(n=224)$

\begin{tabular}{|c|c|c|c|c|c|}
\hline \multirow[t]{2}{*}{ Variables } & \multicolumn{2}{|c|}{ Preference } & \multirow[t]{2}{*}{ COR $(95 \% \mathrm{Cl})$} & \multirow[t]{2}{*}{ AOR $(95 \% \mathrm{Cl})$} & \multirow[t]{2}{*}{ p-value } \\
\hline & TBS & MHF & & & \\
\hline \multicolumn{6}{|c|}{ Admission to a hospital for injury } \\
\hline Yes & 14 & 95 & 1.00 & 1.00 & \\
\hline No & 53 & 62 & $5.801(2.967,11.339)$ & $8.158(1.179,56.44)$ & $0.033^{*}$ \\
\hline \multicolumn{6}{|c|}{ TBS center first port of call after injury } \\
\hline Yes & 61 & 53 & 1.00 & 1.00 & $0.001^{*}$ \\
\hline No & 6 & 104 & $0.050(0.020,0.123)$ & $0.004(0.001,0.090)$ & \\
\hline \multicolumn{6}{|l|}{ Knowledge } \\
\hline Knowledgeable & 16 & 113 & 1.00 & 1.00 & $0.018^{*}$ \\
\hline Not knowledgeable & 51 & 44 & $8.186(4.227,15.852)$ & $9.448(1.481,60.25)$ & \\
\hline \multicolumn{6}{|c|}{ TBS is better than health facility service (Perception) } \\
\hline Yes & 46 & 12 & 1.00 & 1.00 & $0.001^{*}$ \\
\hline No & 13 & 141 & $0.024(0.010,0.056)$ & $0.026(0.003,0.215)$ & 0.184 \\
\hline Don't know & 8 & 4 & $0.522(0.134,2.029)$ & $0.069(0.001,3.567)$ & \\
\hline
\end{tabular}

TBS Traditional Bone Setting, MHF modern health facility, COR Crude odds ratio, AOR adjusted odds ratio, Cl confidence interval

* Statistically significant factors in multivariable analysis

trauma patients who used TBS center as their first port of call after injury (AOR $=0.004,95 \%$ CI $0.001,0.090)$. Trauma patients who weren't knowledgeable about TBS were about 9.5 times more likely to prefer TBS for injury management than those trauma patients who were knowledgeable about $\mathrm{TBS}(\mathrm{AOR}=9.448,95 \% \mathrm{CI}$ 1.481, 60.251). Trauma patients who did not perceive that TBS is better than health facility service in cure were 97.4\% less likely to prefer TBS for injury management as compared to those who perceived that TBS is better than health facility service in cure $(\mathrm{AOR}=0.026,95 \% \mathrm{CI}$ $0.003,0.215$ ) (Table 3).

\section{Discussion}

This study revealed that $29.9 \%$ of the respondents preferred TBS than modern health facilities. The finding indicates that the preference of TBS is high among trauma patients with a fracture. However, this finding is lower compared to a study conducted in Kenya which indicated that $84 \%$ of respondents preferred TBS as their first choice for fracture treatment [17]. Also, it is lower than another study done in Ilorin, North Central Nigeria and Uyo, Nigeria which showed that $69.3 \%$ and $40 \%$ of study participants preferred TBS than modern medicine respectively $[20,21]$. The observed difference might be the majority of the accidents in Ethiopia are road traffic related, and lead to major injuries that need urgent hospital management. In addition, road traffic-related injuries are usually covered by insurance companies and have medico-legal implications pushing for hospital-based management. However, the findings of this study was higher than the finding of the study conducted in Ghana which revealed $25 \%$ of the study participants prefer TBS than modern health facilities [18]. The possible reasons for these differences might be due to differences in the study setting, culture, and socio-demographic characteristics of study participants.

The study showed those trauma patients who were not admitted in the hospital for injury were about eight times more likely to prefer TBS for injury management than those trauma patients who were admitted in the hospital for injury management. This can be explained by the fact that those patients admitted to a hospital for injury management tend to have a major skeletal or other system injury not amenable for traditional bone setters and the care for the admitted patients at the hospital may be good enough to convince the patients to prefer and use modern health facilities. In addition, it might be due to the fact that admitted patients may have enough information about the modern management of fracture through health education or counseling in health facilities.

This study revealed that those patients who did not use TBS center as their first port of call after injury were less likely to prefer TBS for injury management as compared to trauma patients who used TBS center as their first port of call after injury. This might be due to the fact that trauma patients who used modern health care as the first portal of call are more likely to end up being managed in the same place again and again because they may develop confidence and well understand modern fracture management based on the good result of their initial visit. 
As well, the study evidenced that trauma patients who weren't knowledgeable about TBS were 9.4 times more likely to prefer TBS than those trauma patients who were knowledgeable. This might be due to knowing the real pros and cons of being managed by traditional bone setters almost always lead to a preference of modern orthopedic and trauma care.

This study also showed that trauma patients who did not perceive that TBS is better than health facility services in cure were $97.4 \%$ less likely to prefer TBS for injury management as compared to those who perceived that TBS is better than health facilities. This might be due to the fact that perception determines what individuals do, and patients who do not perceive a treatment is curable, will not seek it.

\section{Conclusion}

This study showed that the preference of TBS is high among trauma patients with a fracture. Hospital admission for injury, TBS center as the first port of call after injury, knowledge, and perception were significantly associated with the preference of TBS. Therefore, working more on awareness creation on the need for facilitybased management of trauma patients and the integration of TBS into the health care delivery system in accordance with the WHO recommendation is recommended. Moreover, training and deployment of professionals trained in trauma care to the nearest possible to improve access and quality of the service should be considered.

\section{Limitations}

Even though this study has strengths like using standard and validated tools for data collection, it has limitations as it is the experience of a single public ortho-trauma facility (Black Lion Hospital) and the nature of cross sectional study that may underestimate cause and effect relationship.

\footnotetext{
Abbreviations

FMOH: Federal Ministry of Health; OR: odds ratio; TM: traditional medicine; TBS: Traditional Bone Setting; WHO: World Health Organization.
}

\section{Acknowledgements}

We would like to thank $A B H$ an Affiliate of Jimma University for the support for the realization of this finding. We are also grateful for Black Lion Hospital for the provision of the needed data for our study. Special thanks and appreciation to all those who agreed to participate in this study, mainly respondents, data collectors and supervisors.

\section{Authors' contributions}

NW involved in conception, designing methods, analysis, interpretation and drafting of the manuscript. HM, BA and TT Participated in designing, data analysis, interpretation of the findings and write-up of the findings. All authors read and approved the final manuscript.

\section{Funding}

The study was funded by Jimma University Institute of Health. The organization has no role in the designing of the study, data collection, analysis, and interpretation of data and in writing the manuscript.

\section{Availability of data and materials}

The datasets used and/or analyzed during the current study are available from the corresponding author on reasonable request.

\section{Ethics approval and consent to participate}

Ethical clearance was obtained from research Ethical review board of Institute of Health, Jimma University. The CEO and medical director of Black Lion Hospital and the respondents were verbally and with a letter informed about the study and the objectives of it. Study participants were properly informed about the purpose of the study and informed written consent was sought from study participants. The confidentiality of the respondents was kept and the information collected was used solely for intended purposes.

\section{Consent to publish}

Not applicable.

\section{Competing interests}

The authors declare that they have no competing interests.

\section{Author details}

${ }^{1}$ Black Lion Hospital, Addis Ababa, Ethiopia. ${ }^{2}$ Department of Epidemiology, Institute of Health, Jimma University, Jimma, Ethiopia. ${ }^{3}$ Department of Nursing and Midwifery, Institute of Health, Jimma University, Jimma, Ethiopia.

Received: 26 July 2019 Accepted: 11 September 2019

Published online: 18 September 2019

\section{References}

1. Witmer DK, Marshall ST, Browner BD. Emergency care of musculoskeletal injuries. In: Townsend CM, Beauchamp RD, Evers BM, Mattox KL, editors. Sabiston textbook of surgery. 20th ed. New York: Elsevier; 2016. p. 462-504.

2. Solomon L, Warwick DJ, Nayagam S. Apley's Concise system of orthopaedics and fractures. 3rd ed. New York: Hodder Education Publishers; 2005.

3. WHO. World Health Organization Congress on Traditional Medicine. Beijing, China. 2008.

4. Dada AA, Yinusa W, Giwa SO. Review of the practice of TBSin Nigeria. Afr Health Sci. 2011;11(2):262-5.

5. Green SA. Orthopaedic surgeons, inheritors of tradition. Clin Orthopaedic Relat Res. 1999;363:258-63.

6. Bannerman RH, Burton J, Wen Chieh C. Traditional medicine and health care coverage. Geneva: World Health Organization; 1993.

7. Church J. World Orthopaedic Concern News letter 199. http://www.world orthopaedicconcern.org/

8. Omololu AB, Ogunlade SO, Gopaldasani VK. The practice of traditional bonesetting: training algorithm. Clin Orthop Relat Res. 2008;466(10):2392-8. https://doi.org/10.1007/s11999-008-0371-8.

9. Orjioke CJ. Does traditional medicine have a place in Primary Health Care. Orient J Med. 1995;7(1 and 2):1-3.

10. Thanni LOA. Factors influencing patronage of traditional bonesetters. West Afr J Med. 2000;19(3):220-4.

11. Onuminya JE. The role of the traditional bone setter in Primary fracture care in Nigeria. S Afr Med J. 2004;94(8):652-8.

12. Omololu B, Ogunlade SO, Alonge TO. The complications seen from the treatment by traditional bone setters. West Afr J Med. 2002;21(4):335-7.

13. Solagberu BA. Long bone fractures treated by traditional bonesetters: a study of patients' behaviour. Trop Doct. 2005;35(2):106. https://doi. org/10.1258/0049475054036797.

14. Dessie M. Preventable amputations in Ethiopia. East Cent Afr J Surg. 2004;9(1):8-11 
15. Garba ES, Deshi PJ. TBS: a risk factor in limb amputation. East Afr Med J. 1998;75(9):553-5.

16. Ayele A. Causes of delay among patients seen at the fracture clinic at Menilik II Hospital. East Cent Afr J Surg. 2006;12(2):47-52.

17. Julius R. Knowledge, attitude and practice of TBSin Iftin division Kenya. WAJM. 2016;27(3):345-459.

18. Kuubiere CB, Abass A, Majeed SF. Patients preference for traditional bonesetters in Northern Ghana AIAmeen. J Med Sci. 2015;8(2):115-8.

19. Von Elm E, Altman DG, Egger M, Pocock SJ, Gotzsche PC, Vandenbroucke JP. The strengthening the reporting of observational studies in epidemiology (STROBE) statement: guidelines for reporting observational studies. Lancet. 2007;370(9596):1453-7. https://doi.org/10.1016/S0140 $-6736(07) 61602-X$
20. Nottidge T, Akpanudo E, Akinbami O. Traditional versus orthodox fracture care in uyo, Nigeria. J West Afr Coll Surg. 2011;1(1):53-67.

21. Aderibigbe SA, Agaja SR, Bamidele JO. Determinants of utilization of traditional bone setters in llorin, north central Nigeria. J Prev Med Hyg. 2013:54(1):35-40

\section{Publisher's Note}

Springer Nature remains neutral with regard to jurisdictional claims in published maps and institutional affiliations.
Ready to submit your research? Choose BMC and benefit from:

- fast, convenient online submission

- thorough peer review by experienced researchers in your field

- rapid publication on acceptance

- support for research data, including large and complex data types

- gold Open Access which fosters wider collaboration and increased citations

- maximum visibility for your research: over $100 \mathrm{M}$ website views per year

At BMC, research is always in progress.

Learn more biomedcentral.com/submissions 